\title{
An investigation of formaldehyde concentration in residences and the development of a model for the prediction of its emission rates
}

Article

Accepted Version

Creative Commons: Attribution-Noncommercial-No Derivative Works 4.0

Li, B., Cheng, Z., Yao, R., Wang, H., Yu, W., Bu, Z., Xiong, J., Zhang, T., Essah, E., Luo, Z., Shahrestani, M. and Kipen, H. (2019) An investigation of formaldehyde concentration in residences and the development of a model for the prediction of its emission rates. Building and Environment, 147. pp. 540550. ISSN 0360-1323 doi:

https://doi.org/10.1016/j.buildenv.2018.10.045 Available at https://centaur.reading.ac.uk/80378/

It is advisable to refer to the publisher's version if you intend to cite from the work. See Guidance on citing.

To link to this article DOI: http://dx.doi.org/10.1016/j.buildenv.2018.10.045

Publisher: Elsevier

All outputs in CentAUR are protected by Intellectual Property Rights law, including copyright law. Copyright and IPR is retained by the creators or other copyright holders. Terms and conditions for use of this material are defined in the End User Agreement. 


\section{www.reading.ac.uk/centaur}

\section{CentAUR}

Central Archive at the University of Reading

Reading's research outputs online 


\section{An investigation of formaldehyde concentration in residences and the development of a model for the prediction of its emission rates}

Baizhan Li ${ }^{\mathrm{a}, \mathrm{b}, *}$, Zhu Chenga ${ }^{\mathrm{a}, \mathrm{b}}$, Runming Yao ${ }^{\mathrm{c}}$, Han Wang ${ }^{\mathrm{a}, \mathrm{b}}$, Wei Yu ${ }^{\mathrm{a}, \mathrm{b}}$, Zhongming Bu ${ }^{\mathrm{a}, \mathrm{b}}$, Jie Xiong ${ }^{\mathrm{a}, \mathrm{b}}$, Tujingwa Zhang ${ }^{\mathrm{a}, \mathrm{b}}$, Emmanuel Essah ${ }^{\mathrm{c}}$, Zhiwen Luo ${ }^{\mathrm{c}}$, Mehdi Shahrestani ${ }^{\mathrm{c}}$, Howard Kipen $^{\mathrm{d}}$

a Joint International Research Laboratory of Green Buildings and Built Environments, Ministry of Education, Chongqing University, Chongqing, China

${ }^{\mathrm{b}}$ National Center for International Research of Low-carbon and Green Buildings, Chongqing University, Chongqing, China

${ }^{\mathrm{c}}$ School of the Built Environment, Whiteknights, University of Reading, UK

${ }^{\mathrm{d}}$ Division of Clinical Research and Occupational Medicine Environmental and Occupational Health Sciences Institute; Rutgers University, U.S.A

"Corresponding email: baizhanli@cqu.edu.cn

Highlights:

- $\mathrm{CO}_{2}$ concentration was used as the tracer gas to calculate the indoor ventilation airflow rate;

- Monte-Carlo simulations were conducted for sensitivity analysis;

- A time-averaged effective emission rate predicts the formaldehyde emission rate in residences;

- Occupant activity was taken into account to calculate the emissions.

Abstract: Indoor air pollution caused by formaldehyde associated with building materials imposes a variety of acute and chronic adverse effects on people's health. The aim of this research is to investigate the concentrations of formaldehyde in residences and develop emission rate prediction model in residential buildings. On-site measurements including the indoor and outdoor concentrations of formaldehyde and $\mathrm{CO}_{2}$ were carried out in 42 urban residences in Chongqing. The people occupancy schedule in different functional rooms was obtained by observing the change in $\mathrm{CO}_{2}$ concentration. A robust model for the estimation of formaldehyde emission rates using 
$\mathrm{CO}_{2}$ as the tracer gas; associated with a Monte-Carlo simulation of occupant activities and the characteristics of residences; has been developed. It is revealed that the mean indoor formaldehyde concentration was $30.12 \mu \mathrm{g} / \mathrm{m}^{3}$, which was slightly higher than the outdoor concentration of $27.80 \mu \mathrm{g} / \mathrm{m}^{3}$. The emission rates of $61.82 \pm 52.39$ and $49.69 \pm 42.13 \mu \mathrm{g} / \mathrm{h} / \mathrm{m}^{2}($ mean $\pm \mathrm{SD})$ during the daytime and nighttime, respectively with a daily average of $57.20 \pm 48.79 \mu \mathrm{g} / \mathrm{h} / \mathrm{m}^{2}$. The significant contribution to indoor formaldehyde concentration was from indoor sources. Indoor formaldehyde source control is suggested to be an efficient way to control the indoor concentration.

Key words: indoor air quality (IAQ); formaldehyde; air exchange rate; emission rate

\section{Introduction}

Volatile organic compounds (VOCs) are one of the main sources of indoor air pollution. As the most commercially used aldehyde, formaldehyde is widely used in construction, wood processing, furniture, textiles, carpeting, and the chemical industry ${ }^{[1][2]}$. China is the single-largest market for formaldehyde, accounting for $47 \%$ of world demand in $2017^{[3]}$. Due to the economic boom in recent decades, intensive interior decoration and renovation of homes became very popular in China ${ }^{[4]}$ for the purpose of creating more aesthetically pleasing home environments. More than $65 \%$ of formaldehyde production goes to produce synthetic resins used in building materials ${ }^{[1]}$. For example, interior decoration materials such as wood, wallpaper, paint, and household consumer products like floor cleaning agents, candles, and electric air fresheners ${ }^{[5]}$ would release formaldehyde into the indoor environment. Meanwhile, 
formaldehyde has been detected in exhaled air using modern analytical techniques and has even been linked to various diseases. Compounds, particularly aldehydes, have to be considered with great care since their elevated exhaled level might reveal a relationship to exposure to air pollutants ${ }^{[6]}$.

Making buildings airtight in an attempt to improve energy efficiency by decreasing the infiltration of unconditioned outdoor air ${ }^{[7]}$ could potentially contribute to lowerquality indoor air due to lack of ventilation.

It is reported that the indoor air pollution caused by formaldehyde associated with building materials imposed a variety of acute and chronic adverse effects on people's health $^{[1][4][8]}$ such as symptoms of Sick Building Syndrome (SBS), lower respiratory and eye irritation, acute poisoning, dermal allergies, allergic asthma, neurotoxicity, pulmonary function damage, and potential carcinogenic effects. The situation has attracted considerable public attention in recent years in terms of their health and wellbeing. The mechanism for the emission and release of pollutants from materials has been extensively studied in recent decades ${ }^{[9][10]}$ including onsite measurements and numerical modelling aimed at developing methods that can reduce exposure to indoor VOCs and improve IAQ $\mathrm{I}^{[11][12][13][14][15]}$.

Environment chamber experiments and modeling are usually employed to study the formaldehyde emission characteristics such as the decay time ${ }^{[16][17]}$. However, it is hard to use such experimental data to predict the real conditions in buildings because of uncertainties such as the interaction of human activities and the nature of dynamic 
infiltration in real cases ${ }^{[18]}$. On the other hand, measurement of the emission rates of formaldehyde in an actual indoor environment could be costly and impractical.

One alternative method is to measure the concentration of formaldehyde in the indoor and outdoor environment and then to back-calculate the effective emission rates $^{[19][20][21]}$. According to the standard mass-balance model ${ }^{[21]}$, indoor formaldehyde concentration is inversely proportional to the air exchange rate. A developed massbalance model was used to differentiate indoor-outdoor concentration ratios and to separate indoor and outdoor sources, but it did not contain building characteristics $^{[22][23][24][25][26][27]}$. Riley et al. $^{[28]}$ developed the model by specifically considering building operational characteristics (i.e. filtration, penetration, deposition, and ventilation), but some of the parameters, such as air exchange rates, were assumed and the indoor sources of emissions were ignored. This model was then used to predict the proportion of pollutants outdoors and indoors considering natural ventilation. The limitation of these studies is the ignorance of occupant activities ${ }^{[29]}$. For example, the model developed by Rackes et al. ${ }^{[30]}$ based on the 24-hour time-average pollutant concentration and occupant respiratory effects was used to predict the indoor pollutant emission rate which accounts for all indoor pollutant sources. In addition, the occupancy schedule was not considered.

Turk et al. ${ }^{[31]}$ investigated 40 houses approximately one-year old or newer with air exchange rates of at least $0.13 / \mathrm{h}$ using passive techniques and found the average formaldehyde emission was $90 \pm 55 \mu \mathrm{g} / \mathrm{h} / \mathrm{m}^{2}$. The outcomes of this study revealed that 
the emission rate of formaldehyde in new buildings was relatively high. The effective emission rate of formaldehyde in typical new houses in North America was estimated to be $44 \pm 16 \mu \mathrm{g} / \mathrm{h} / \mathrm{m}^{2}$ using the backward calculation method, but this research assumed that all the formaldehyde is released from building materials ${ }^{[32]}$. Kim et al. ${ }^{[33]}$ calculated the average emission rates of formaldehyde using 5 different sources in 19 private reading rooms. This was $45 \pm 38 \mu \mathrm{g} / \mathrm{h} / \mathrm{m}^{2}$ and concluded that it was impossible to find all the emission sources.

Because the impact of various sources would significantly influence the accuracy of the results, the emission rate obtained from traditional methods is usually not directly applicable to real buildings.

It was demonstrated in a previous study ${ }^{[34]}$ that formaldehyde posed the highest risk to people's health. Previous studies have found that the concentrations of formaldehyde in buildings in Chongqing were higher than for other types of VOCs ${ }^{[35]}$. It remains questionable whether the formaldehyde concentration in residences considers human interactions and what the emission rate would be. In order to fill the research gap, this study aims to gain a better understanding of the current situation of indoor formaldehyde pollution in residences and to reveal its emission mechanism using onsite measurements and a numerical approach. Furthermore, this study attempted to test whether the formaldehyde emissions from humans will affect the indoor concentration. The work then concentrated on the following aspects: 1) to collect $\mathrm{CO}_{2}$ real-time data and formaldehyde concentration data via on-site measurement in real residences as well as 
their occupancy pattern; 2) to calculate ventilation rates using $\mathrm{CO}_{2}$ emission as the tracer gas; 3) to develop a robust model for the estimation of formaldehyde emission rates. Detailed descriptions are presented in the following sections.

\section{Method}

The onsite measurements were carried out in 42 residences in Chongqing during the period between November 2015 and January 2016. The information about the building characteristics of these residences and the structure of the families living there were obtained through a questionnaire survey involving a brief information sheet. The measurements of the parameters included room dimensions, indoor/outdoor air temperatures and the indoor/outdoor concentrations of $\mathrm{CO}_{2}$ and formaldehyde.

\subsection{Sampling site}

The on-site measurements were conducted in the urban districts of Chongqing, i.e. Shapingba (SPB), Jiangbei (JB), Yubei (YB), Banan (BN), Nanan (NA), Yuzhong (YZ), Dadukou (DDK), Jiulongpo (JLP), and Beibei (BB), as shown in Fig. 1. In 2005, the Chinese government published a national standard 'Code for Indoor Environmental Pollution Control of Civil Building Engineering' (GB50325-2005) ${ }^{[36]}$, this standard required the quality of civil buildings built after 2005 to be of better quality than those built before 2005. The age band of the buildings in this study ranged from 2005 to 2012 . Nine of all the measured residences had been renovated; the most recent renovation was 4 years prior to this study. The buildings are reinforced concrete structures. The lowest residential apartment is on the first floor and the highest residential apartment is on the 
27th floor. 20 residential apartments are located below the 10th floor. The characteristics of the measured residences are shown in Table 1.

Table 1: Characteristics of residential apartments

\begin{tabular}{|c|c|c|c|}
\hline Functional room & Living room & Bedroom & Kitchen \\
\hline \multirow{2}{*}{ Floor Materials } & Wood (n=14) & Wood $(n=37)$ & Wood $(n=3)$ \\
\hline & Tile $(n=28)$ & Tile $(n=5)$ & Tile $(n=39)$ \\
\hline \multirow{2}{*}{ Wall Materials } & Wallpaper $(\mathrm{n}=15)$ & Wallpaper $(\mathrm{n}=15)$ & Ceramic tile $(n=38)$ \\
\hline & Latex paint $(\mathrm{n}=27)$ & Latex paint $(\mathrm{n}=27)$ & Latex paint $(n=4)$ \\
\hline \multirow{2}{*}{ Ceiling Materials } & Paint $(n=1)$ & Paint $(\mathrm{n}=1)$ & Paint $(\mathrm{n}=1)$ \\
\hline & Latex paint $(n=41)$ & Latex paint $(n=41)$ & Latex paint $(\mathrm{n}=41)$ \\
\hline \multirow{4}{*}{ Window Materials } & Single layer glass & Single layer glass & Single layer glass \\
\hline & $(n=39)$ & $(n=37)$ & $(n=37)$ \\
\hline & double-layered glass & double-layered glass & double-layered glass \\
\hline & $(n=3)$ & $(\mathrm{n}=5)$ & $(\mathrm{n}=5)$ \\
\hline \multirow{3}{*}{$\begin{array}{c}\text { Window Frame } \\
\text { Materials }\end{array}$} & Wood $(n=1)$ & Wood $(n=1)$ & Wood $(n=1)$ \\
\hline & Aluminum alloy (34) & Aluminum alloy (34) & Aluminum alloy (34) \\
\hline & Plastic (7) & Plastic (7) & Plastic (7) \\
\hline \multirow{3}{*}{ Quantity } & & $1(n=5)$ & \\
\hline & $1(n=42)$ & $2(n=25)$ & $1(n=42)$ \\
\hline & & $3(n=12)$ & \\
\hline
\end{tabular}

The selection of residences for this research was based on the following criteria: 1 ) the residences were occupied without any renovation within the last year to avoid excessive concentration values skewing the test results; 2) all the residences had to be at least $100 \mathrm{~m}$ away from the main roads to avoid the influence of vehicle emissions ${ }^{[37]}$; 3) all the residences were located in the main urban areas with relatively high population densities, which is representative of the characteristics of developing urban areas in China; 4) the house owners were informed about the details of the investigation during the whole sampling process; 5) during the field test, natural ventilation was the only way for fresh air to enter the residences. 


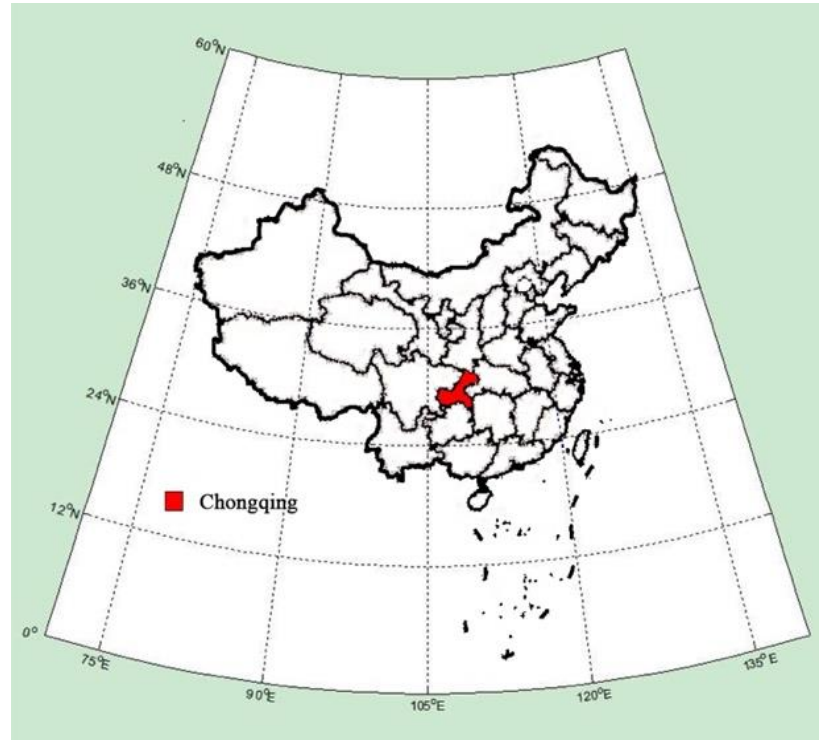

(a) Location of Chongqing

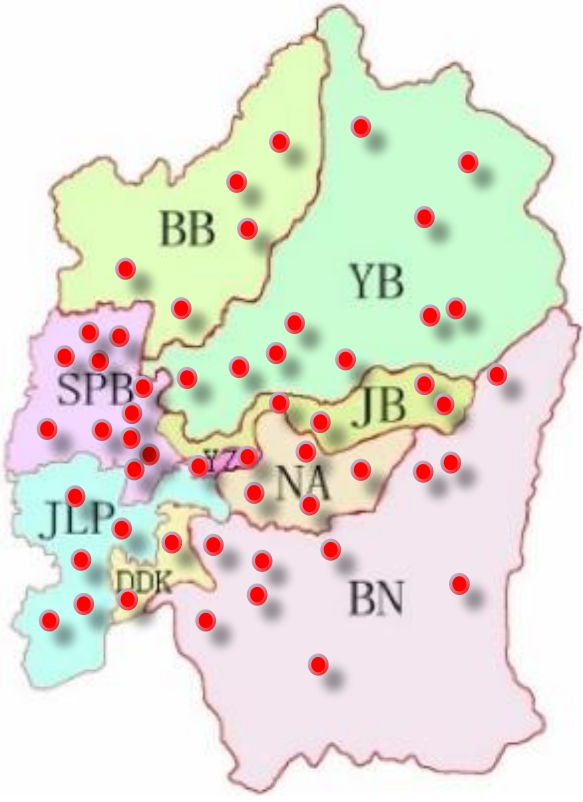

(b) Location of sampled buildings highlighted within the urban areas of Chongqing

Fig. 1: Illustrates (a) the location of Chongqing and (b) the areas investigated within Chongqing.

\subsection{Data collection}

\section{I) Onsite measurement}

For formaldehyde, there was one pair of sampling points for each residence, one placed in the living room and the other outdoors. For $\mathrm{CO}_{2}$, there were four sampling points placed in the living room, bedroom, kitchen and outdoor space respectively. Because formaldehyde concentration levels in different rooms were very similar ${ }^{[34]}$, this research only measured the formaldehyde concentration in the living room. The indoor sampling points were evenly distributed on the diagonal of each room as shown in Fig. 2 (a) i.e. as a quincunx. The number of sampling points was chosen based on the room size. If the room area was 1) less than $50 \mathrm{~m}^{2}$, set $1-3$ sampling points; 2) $50-100 \mathrm{~m}^{2}$, set 3-5 sampling points; 3) more than $100 \mathrm{~m}^{2}$, set at least five sampling points. As all the rooms were smaller than $50 \mathrm{~m}^{2}$, we only used one measuring point in each room. Samplers were placed at approximately $1.5 \mathrm{~m}$ above the floor and more than $0.5 \mathrm{~m}$ from 
the walls, windows and doors, or located as centrally as possible within these given constraints $^{[38]}$. Figure 2(b) shows a typical arrangement for the locations of sensors in a room and outdoor. The geometric parameters of the residences were measured by a laser distance meter (424D, Fluke Corp.). The outdoor sampling points were set at $1.5 \mathrm{~m}$ away from the windows. For most Chinese residential apartments, there are only 4 different function rooms: the living room, bedroom, kitchen and bathroom. The bathroom decoration materials are different from those in the other rooms. Moreover, the bathroom always has a mechanical ventilation system and has its door closed most of the time. Hence, it was assumed that the 3 function rooms (living room, bedroom and kitchen) can represent the whole apartment.

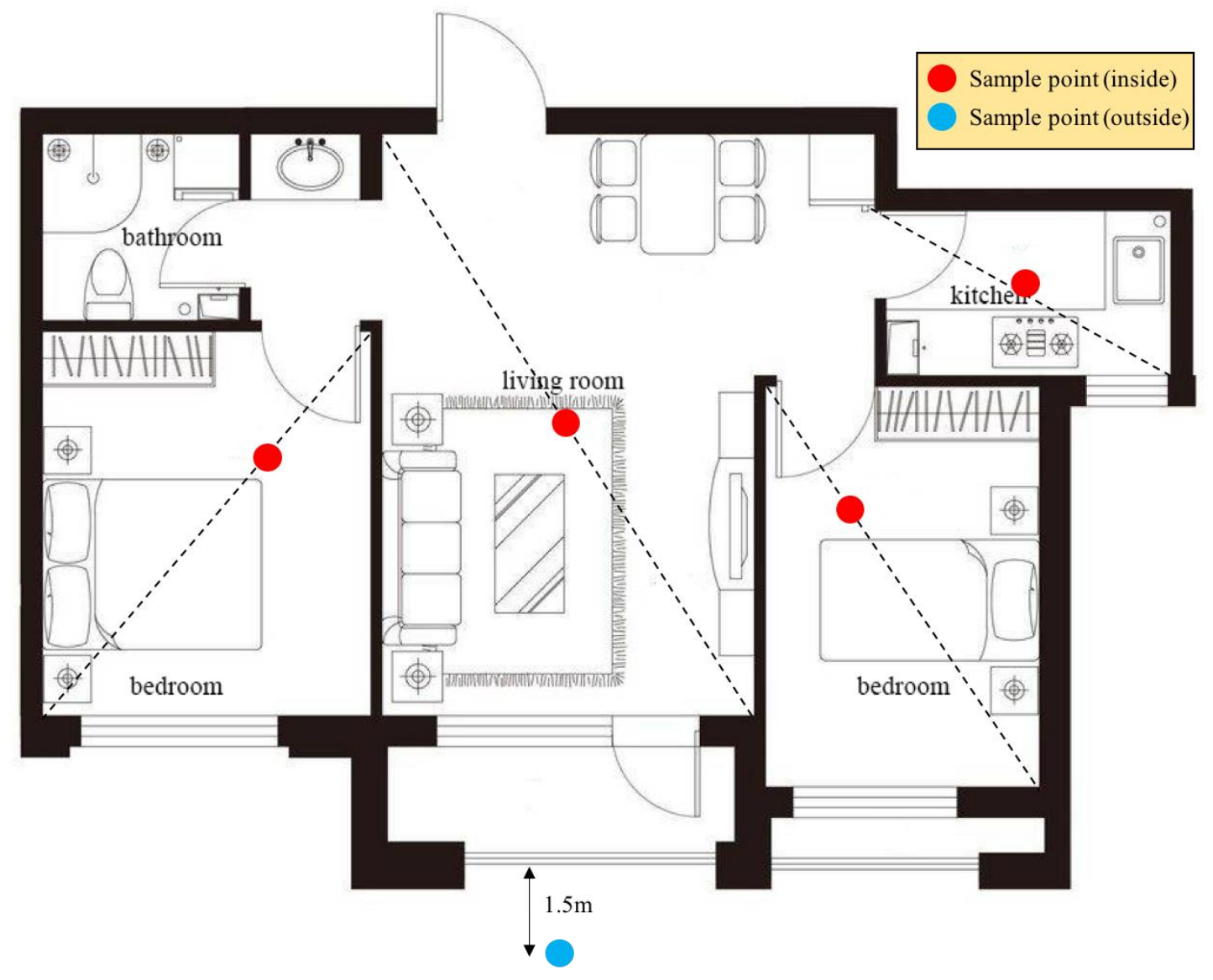

(a) The illustration of sampling points in a typical residence 

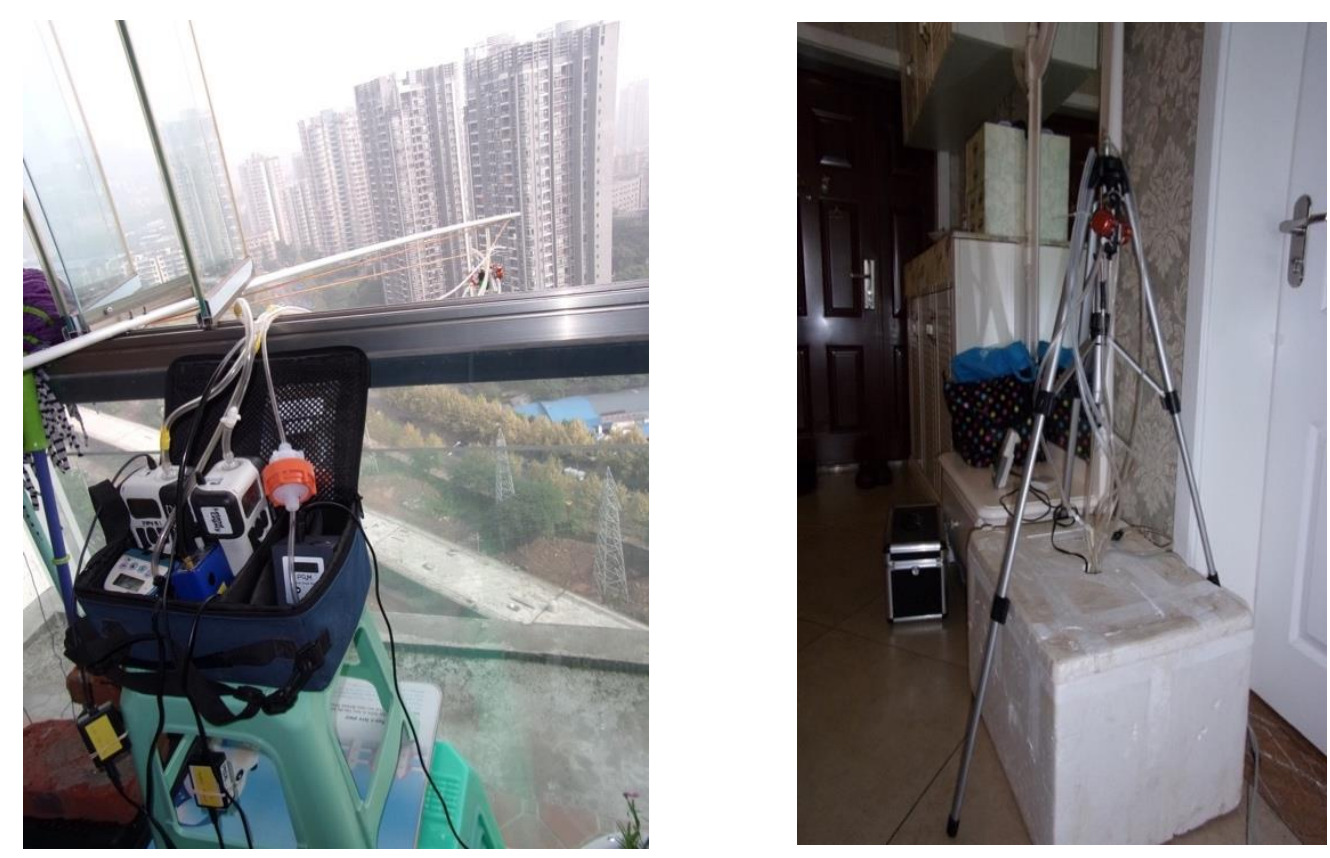

(b) The sampling points in and outside a residence

II) Data collection

Fig. 2: The sampling points.

For each residence, the temperature, relative humidity, and $\mathrm{CO}_{2}$ concentration indoors and outdoors were recorded continuously for 24 hours, for time intervals of 1 minute. A carbon dioxide detector (Telaire 7001, General Electric Co.) was used to monitor the $\mathrm{CO}_{2}$ concentration. An automatic temperature and humidity logger (HOBO U-12, Onset Computer Corp.) was used to monitor the temperature and humidity.

III) Air samples

Air samples were collected by a Passive Sampler (Chinese Center for Disease Control and Prevention (CDC)) for 24 hours. According to the 'Chinese Standard Method for Hygienic Examination of Formaldehyde in the Air of Residential Areas' the Spectrophotometric method (GB/T 16129-1995) ${ }^{[39]}$ - formaldehyde was absorbed by a 4-amino-3-hydrazino-5-mercapto-1,2,4-triazole (AHMT) solution and analyzed using a UV-VIS spectrometer (7205, Xinmao Corp.) at 550nm. Samples must be placed in a pouch, and the pouch must be sealed, refrigerated and stored at $4{ }^{\circ} \mathrm{C}$ before and after use. The sample must be analyzed within three weeks. The detection limit (MDL) of this 
method was $0.01 \mathrm{mg} / \mathrm{m}^{3}$ and the relative standard deviation (RSD) was less than $10 \%$. The recovery rates for formaldehyde samplers ranged from $90 \%-100 \%$ and the limit of detection (LOD) value of this method is $0.22 \mu \mathrm{g} / 10 \mathrm{ml}$. Table 2 shows the parameters of the measuring instruments.

Table 2: Parameters of the measuring instruments.

\begin{tabular}{|c|c|c|c|c|c|}
\hline Model & Company & $\begin{array}{l}\text { Measuring } \\
\text { variable }\end{array}$ & Range & Accuracy & Resolution \\
\hline Telaire 7001 & $\begin{array}{l}\text { General Electric } \\
\text { Co. }\end{array}$ & $\mathrm{CO}_{2}$ & $0-2500 \mathrm{ppm}$ & $\begin{array}{l} \pm 50 \text { ppm or } \\
5 \% \text { of reading }\end{array}$ & $\pm 1 \mathrm{ppm}$ \\
\hline & General Electric & Temperature & $-20-70^{\circ} \mathrm{C}$ & $\begin{array}{l} \pm 0.35^{\circ} \mathrm{C} \text { from } \\
0-50^{\circ} \mathrm{C}\end{array}$ & $0.03^{\circ} \mathrm{C}$ \\
\hline & Co. & Humidity & $5 \%-95 \%$ RH & $\begin{array}{l} \pm 2.5 \% \text { from } \\
10 \%-90 \% \mathrm{RH}\end{array}$ & $0.05 \% \mathrm{RH}$ \\
\hline $\begin{array}{l}\text { Passive } \\
\text { Sampler }\end{array}$ & $\mathrm{CDC}$ & Formaldehyde & $10-130 \mu \mathrm{g} / \mathrm{m}^{3}$ & $\begin{array}{l}\text { Lower than } \\
10 \%\end{array}$ & - \\
\hline 7205 & Xinmao Corp. & Wavelength & $325-1000 \mathrm{~nm}$ & $\pm 2 \mathrm{~nm}$ & $\pm 1 \% \mathrm{~T}$ \\
\hline 424D & Fluke Corp. & Distance & $0-100 \mathrm{~m}$ & $\pm 1 \mathrm{~mm}$ & $\pm 1 \mathrm{~mm}$ \\
\hline
\end{tabular}

\subsection{Statistical analysis}

To investigate the distribution of these data and their principal characteristics, statistical analyses were performed using SPSS (a Statistical Package for Social Science, Version 25, IBM Corp.) to ensure a significance level of $\mathrm{p}=0.05$ as the benchmark. In addition, Pearson Correlation is used to investigate if there is a statistically significant difference between indoor and outdoor formaldehyde levels, and the Shapiro-Wilks test was applied to examine whether the pollution concentration dataset fit revealed a normal or lognormal distribution. In this research, the distribution of formaldehyde concentration matches the lognormal distribution, according to the P-P plot. Since 
formaldehyde concentrations were not normally distributed, the lognormal transformed formaldehyde concentrations were used in the Monte Carlo simulations as explained in Section 2.4.

\subsection{Uncertainty and sensitivity analysis}

A prediction using single point values can result in great uncertainty ${ }^{[40]}$, whereas stochastic modeling can provide a more accurate emission rate compared with one that only uses field test data. The building characteristics, outdoor and indoor concentrations, and the number of people staying in a residence are useful when the Monte Carlo method is used to estimate the emission rate. Monte Carlo simulations are used to model the probability of different outcomes in a process that cannot easily be predicted due to the intervention of random variables. It is a technique used to understand the impact of risk and uncertainty in prediction and forecasting models and relies on repeated random sampling to obtain numerical results. A sensitivity analysis determines how different values of an independent variable impact on a particular dependent variable under a given set of assumptions. This technique is used within specific boundaries that depend on one or more input variables, such as the effect that changes in independent variables have on the dependent variable. In this study, the Monte-Carlo simulation and sensitivity

analysis were conducted using Oracle Crystal Ball software (Fusion Edition, V. 11.1.2.4). 1,000,000 trials of Monte-Carlo simulations were performed to calculate the emission rate $^{[41]}$. 


\subsection{Ventilation airflow rate model}

The tracer gas method is one of the approaches that can be used to calculate the air exchange rate in naturally ventilated residences, however, its use is limited because 1) tracer gas equipment takes up a lot of space; 2) tracer gas and indoor air need to be evenly mixed by a hybrid fan first ${ }^{[42][43]}$.

Although using $\mathrm{CO}_{2}$ as the tracer gas may result in uncertainties, it is the best choice for field tests in residences. In this study, $\mathrm{CO}_{2}$ was used as the tracer gas to calculate the indoor ventilation airflow rate. The $\mathrm{CO}_{2}$ concentration rises when people stay in a room and decreases when they leave. A calculation method - the PIT (Parametric Iteration Technique) - is used to calculate the air exchange rate ${ }^{[44]}$. The increase of $\mathrm{CO}_{2}$ concentration $(\Delta c)$ for each time interval $(\Delta \tau)$ is related to the instantaneous airflow rate as in the equation below which assumes a uniform distribution of indoor $\mathrm{CO}_{2}$ :

$$
\begin{gathered}
\Delta c=\frac{\Delta \tau}{V_{a}}\left[F_{C O_{2}}-N_{a} V_{a}\left(c_{1}-c_{\text {out }}\right)\right] \\
\Delta c=c_{2}-c_{1} \\
F_{C O_{2}}=R Q \frac{0.00056028 H^{0.725} W^{0.425} M}{(0.23 R Q+0.77)}
\end{gathered}
$$

Where $N_{a}\left(\mathrm{~h}^{-1}\right)$ is the ventilation airflow rate; $c_{1}(\mathrm{ppm})$ is the concentration of $\mathrm{CO}_{2}$ in the indoor environment at the beginning; $c_{2}(\mathrm{ppm})$ is the subsequent indoor $\mathrm{CO}_{2}$ concentration; $c_{\text {out }}(\mathrm{ppm})$ is the concentration of $\mathrm{CO}_{2}$ in the outdoor environment; $\Delta \tau$ (s) is the time step; $\Delta c(\mathrm{ppm})$ is the $\mathrm{CO}_{2}$ concentration change during $\Delta \tau ; V_{\mathrm{a}}\left(\mathrm{m}^{3}\right)$ is the room volume; $F_{\mathrm{CO}_{2}}\left(\mathrm{~m}^{3} / \mathrm{s}\right)$ is the emission rate in the indoor environment; $R Q$ is the respiratory quotient, treated as a constant $=0.83 ; H(\mathrm{~cm})$ is the height of a person in the 
indoor environment; $W(\mathrm{~kg})$ is the weight of a person in the indoor environment; and $M$ (met) is the metabolic rate.

The relationship between indoor $\mathrm{CO}_{2}$ concentrations at times $\tau_{\mathrm{k}}$ and $\tau_{\mathrm{k}-1}$ can be obtained:

$$
C_{1}(k)=\frac{\Delta \tau}{V_{a}}\left\{F R_{\text {all }}-N_{a} V_{a}\left[C_{1}(k-1)-C_{\text {out }}\right]\right\}+C_{1}(k-1)
$$

where $F R_{\text {all }}\left(\mathrm{m}^{3} / \mathrm{s}\right)$ is the $\mathrm{CO}_{2}$ emission rate from all the occupants.

A theoretical exponential curve was obtained by iteratively calculating the concentration for each time step. Then the least squares method was used to fit the theoretical exponential curve and the measured data. At a particular moment, the actual indoor concentration is $C_{1}(k)$ and the predicted indoor concentration is $C_{1}^{\prime}(k)$. From the result of the optimal fitting, the ventilation airflow rate is calculated to achieve the the smallest error.

$$
\text { Error }=\left(C_{1}(k)-C_{1}^{\prime}(k)\right)^{2}
$$

The outdoor concentration of $\mathrm{CO}_{2}$ barely changes during the measurements. Therefore, this study used the outdoor concentration of $\mathrm{CO}_{2}$ recorded 30 minutes before the field test as the background concentration and recorded the occupant's time distribution in the indoor environment, the height and weight of the occupant, the volume of rooms, and the arrangement of doors and windows during the test.

The ventilation airflow rate was calculated by using MATLAB (R2015b, MathWorks, Inc.). 


\subsection{IAQ model}

A steady-state model was used in this research since the data for the concentration of formaldehyde was not dynamic but averaged over 24 hours. Moreover, the fluctuations in the $\mathrm{CO}_{2}$ concentration were also unsuitable for dynamic modeling. For any indoor pollutant, the change of concentration is related to its source emission and exhaust rates ${ }^{[21][30]}$, see equation (6) below:

$$
C_{e}=N\left(C_{\text {in }}-C_{\text {out }}\right)
$$

Where $C_{e}$ is the emission rate $\left(\mu \mathrm{g} / \mathrm{m}^{3} / \mathrm{h}\right) ; N\left(\mathrm{~h}^{-1}\right)$ is the air exchange rate, $C_{\text {in }}\left(\mu \mathrm{g} / \mathrm{m}^{3}\right)$ is the indoor concentration; and $C_{\text {out }}\left(\mu \mathrm{g} / \mathrm{m}^{3}\right)$ is the outdoor concentration.

The air exchange rate $(N)$ is the total of the ventilation exchange rate $\left(N_{\text {vent }}\right)$ and the infiltration rate $\left(N_{\mathrm{inf}}\right)$.

$$
N=N_{\text {vent }}+N_{\text {inf }}
$$

Also,

$$
N=\frac{Q_{v e n t}+Q_{\text {inf }}}{V_{a}}
$$

Where $Q_{\text {vent }}\left(\mathrm{m}^{3} / \mathrm{h}\right)$ is the ventilation airflow rate and $Q_{\text {inf }}\left(\mathrm{m}^{3} / \mathrm{h}\right)$ is the infiltration airflow rate, $V_{a}\left(\mathrm{~m}^{3}\right)$ is the volume of the room.

$$
\begin{gathered}
C_{e} V_{a}=\left(C_{\text {in }}-C_{\text {out }}\right)\left(Q_{\text {vent }}+Q_{\text {inf }}\right) \\
C_{e} V_{a}=E_{p} P_{a}+E_{a} A_{a}
\end{gathered}
$$

$E_{\mathrm{p}}(\mu \mathrm{g} / \mathrm{h} / \mathrm{occ})$ is the emission rate per-occupant and $E_{\mathrm{a}}\left(\mu \mathrm{g} / \mathrm{h} / \mathrm{m}^{2}\right)$ is the emission rate per-floor-area. $P_{\mathrm{a}}(\mathrm{occ})$ is the number of occupants and $A_{\mathrm{a}}\left(\mathrm{m}^{2}\right)$ is the floor area.

$$
C_{\text {in }}=C_{\text {out }}+\frac{E_{p} P_{a}+E_{a} A_{a}}{Q_{\text {vent }}+Q_{\text {inf }}}
$$


In this research, the concentration levels of formaldehyde were divided into nighttime and day-time, because occupants' activities are very different over a 24-hour period, meaning that time distribution must be taken into account. In this research, we separate the whole day into two parts, one is day-time, and the other night-time. We defined the night as from 18:30 pm. to 07:30 am. The rest of the time is considered as day-time.

\subsection{Formaldehyde emission rate}

According to the IAQ model ${ }^{[30]}$, the value of $E_{\mathrm{a}}$ can be calculated as follows:

$$
\begin{gathered}
E_{a}=\frac{\left(C_{\text {in }}-C_{\text {out }}\right)\left(Q_{\text {vent }}+Q_{\text {inf }}\right)-E_{p} P_{a}}{A_{a}} \\
E_{a}=\frac{\left(C_{\text {in }}-C_{\text {out }}\right)\left(N V_{a}\right)-E_{p} P_{a}}{A_{a}}
\end{gathered}
$$

where $C$ means the concentration of formaldehyde and $E_{\mathrm{a}}$ means the per-floor-area emission rate of formaldehyde.

This model contains the air exchange factor and in particular the human breathing factor. It was shown to provide more accurate result than previous studies.

When the indoor concentrations were smaller than the outdoor concentration, the above equation cannot give a reasonable result. Also, when the occupants' exhalation emissions were high enough to make the denominator negative, no reasonable result could be obtained. In this research, the data were filtered to ensure reasonable emission values. 


\section{Results and discussion}

\subsection{Formaldehyde concentration}

The concentration of formaldehyde was conducted by field measurements. The indoor formaldehyde sources were indoor building materials and occupant exhalation. The data set consists of 42 indoor and 42 outdoor formaldehyde concentration measurements.

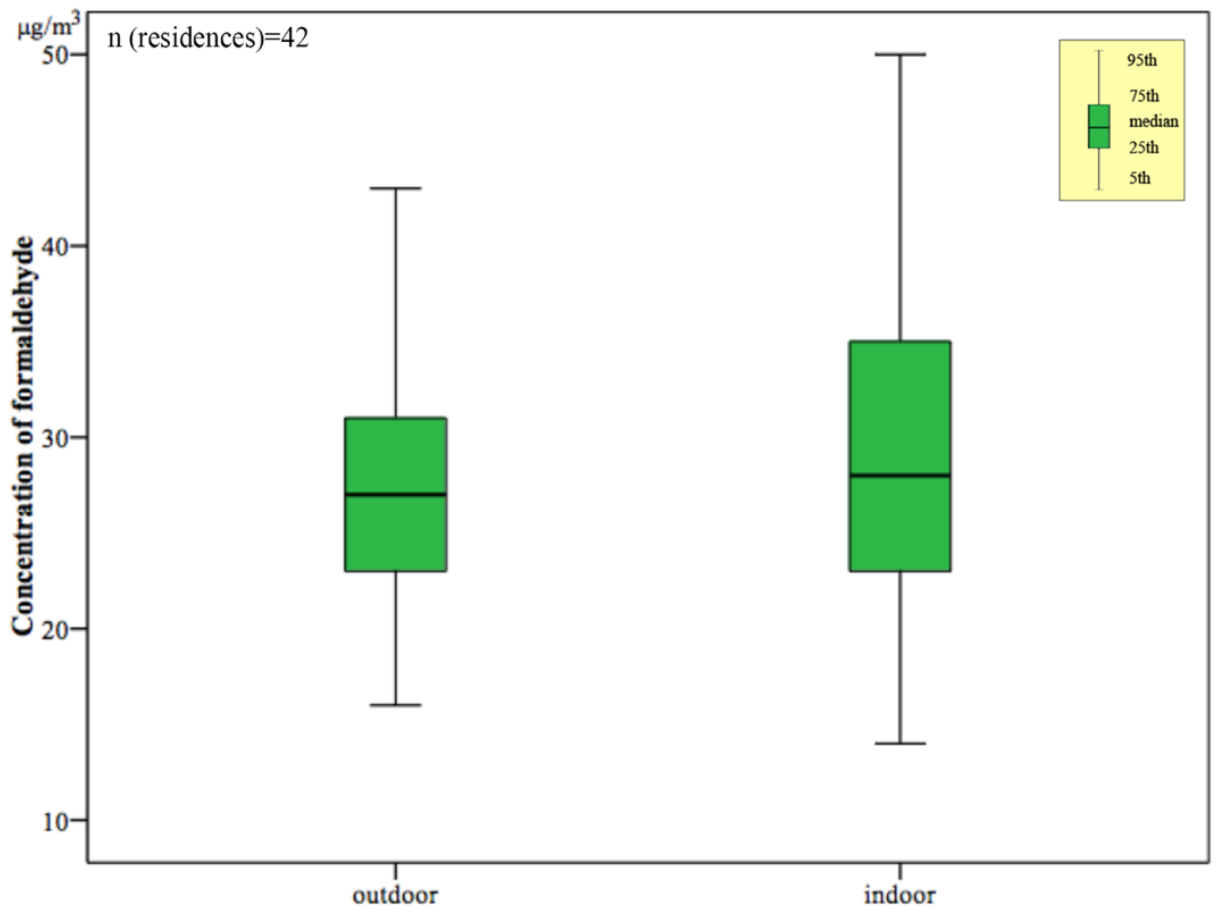

Fig. 3: The concentration of formaldehyde.

As shown in Fig. 3, the indoor concentration of formaldehyde was slightly higher than that of the outdoor environment and the mean concentrations of formaldehyde indoors and outdoors were $30.12 \mu \mathrm{g} / \mathrm{m}^{3}$ and $27.80 \mu \mathrm{g} / \mathrm{m}^{3}$ respectively. However, the $5^{\text {th }}$ percentile value to the $95^{\text {th }}$ percentile value of the indoor and outdoor formaldehyde concentrations were $18.10 \mu \mathrm{g} / \mathrm{m}^{3}$ to $49.00 \mu \mathrm{g} / \mathrm{m}^{3}$ and $19.10 \mu \mathrm{g} / \mathrm{m}^{3}$ to $42.90 \mu \mathrm{g} / \mathrm{m}^{3}$, respectively. It shows that it is possible for some residences to have a lower indoor 
formaldehyde concentration than outdoor. The I/O ratios were in the range of 0.51 to 1.88, around $60 \%$ of which were greater than 1. Fig. 4 indicates the significant contribution from indoor sources. According to the statistical analyses results, the $p$ value of Pearson correlation is 0.487 , and Pearson correlation coefficient is 0.112 which means indoor formaldehyde concentration levels are not significantly associated with outdoor formaldehyde concentration levels.

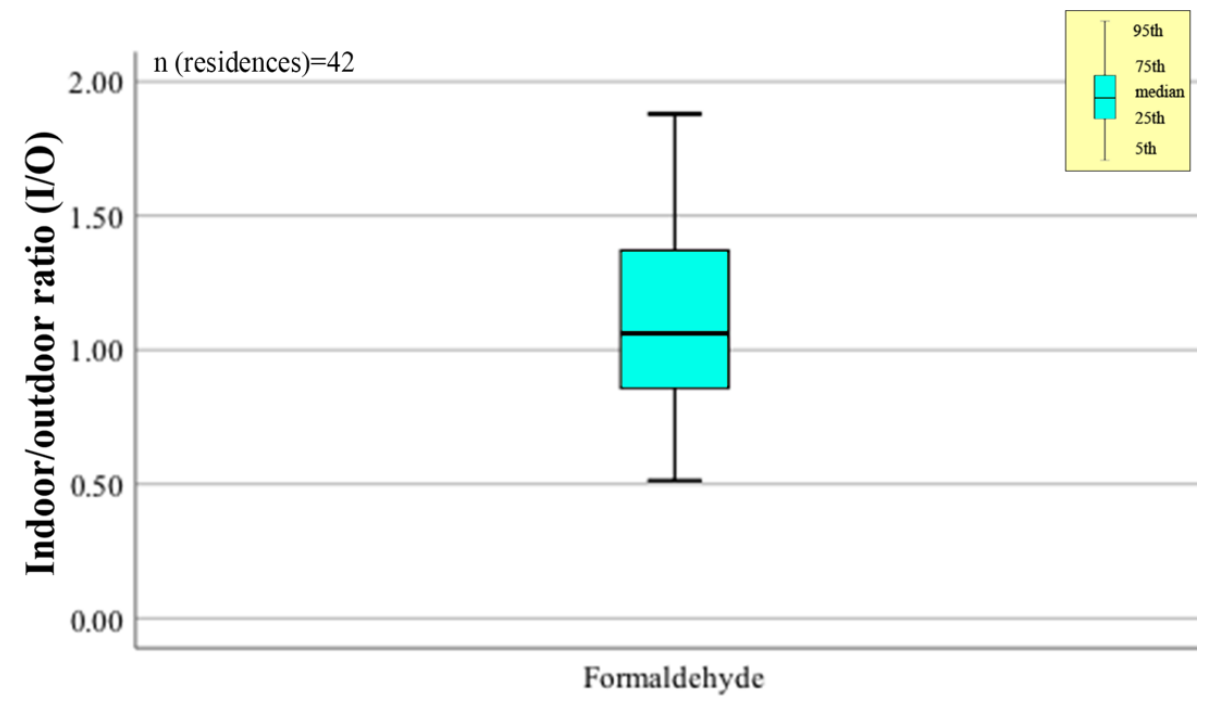

Fig. 4: The I/O ratio of formaldehyde.

Table 3: Formaldehyde concentration limits

\begin{tabular}{ccc}
\hline Pollutant & Class 1 civil engineering & Class 2 civil engineering \\
\hline Formaldehyde $(\mu \mathrm{g} / \mathrm{m} 3)$ & $\leq 80$ & $\leq 100$ \\
\hline
\end{tabular}

According to the 'Chinese Standard Code for Indoor Environmental Pollution Control of Civil Building Engineering' (GB50325-2010) ${ }^{[45]}$, the concentration limit of formaldehyde in civil buildings is $80 \mu \mathrm{g} / \mathrm{m}^{3}$ for Class 1 civil buildings, as shown in Table 3 and the concentrations of formaldehyde did not exceed this limit. China only provides guideline values for short-term (1h) exposure to the indoor environment, which are set out in the 'Chinese Standard' (GB/T 18883-2002) $)^{[38]}$, and the concentration limit for formaldehyde is $100 \mu \mathrm{g} / \mathrm{m}^{3}$. In this study, the mean concentration of formaldehyde 
measured in Chongqing residences was within the short-term limit. Here it should be mentioned that the short-term exposure to formaldehyde in residences might have no perceptible effect on human health.

Formaldehyde was detected with a frequency of $100 \%$, which means that formaldehyde was one of the common pollutants in Chongqing residences. Compared with other research studies in China (Table 4), the concentration of formaldehyde in the indoor environment was similar to the concentration in Dalian $\left(32.9 \mu \mathrm{g} / \mathrm{m}^{3}\right)^{[46]}$, lower than the concentration in Tianjin $\left(54 \mu \mathrm{g} / \mathrm{m}^{3}\right)^{[47]}$, Harbin $\left(72.5 \mu \mathrm{g} / \mathrm{m}^{3}\right)^{[48]}$ and Beijing $\left(131 \mu \mathrm{g} / \mathrm{m}^{3}\right)^{[4]}$ and slightly higher than the concentration in Chongqing $\left(20 \mu \mathrm{g} / \mathrm{m}^{3}\right)$ obtained by another study ${ }^{[34]}$. The lower concentration of formaldehyde in Chongqing published in a previous study may come from its use of active sampling and different chemical analysis methods ${ }^{[34]}$. Compared to results from other countries (Table 4), except for Helsinki $\left(39.96 \mu \mathrm{g} / \mathrm{m}^{3}\right)^{[49]}$ and Strasbourg $\left(32.3 \mu \mathrm{g} / \mathrm{m}^{3}\right)^{[50]}$ which were slightly higher than the current research, other places like Quebec ${ }^{[51]}$, New York ${ }^{[52]}$, Los Angeles $^{[52]}$, Houston and Elizabeth ${ }^{[53]}$ gave lower results than in the current research, especially the concentration of formaldehyde of Melbourne ${ }^{[54]}$ which was only $14.64 \mu \mathrm{g} / \mathrm{m}^{3}$. Comparing the formaldehyde concentration of Chinese cities to those from other developed countries, China's indoor formaldehyde concentration level is significantly higher.

Table 4: Comparison of formaldehyde level (mean) tests of air samples from residences $\left(\mu \mathrm{g} / \mathrm{m}^{3}\right)$

\begin{tabular}{|c|c|c|c|c|}
\hline Reference & Country & Sampling information & type & formaldehyde \\
\hline Current study & Chongqing, China & $\mathrm{n}=42$ & & 30.12 \\
\hline Huang et al. (2013) & Beijing, China & $n=410$ & & 131 \\
\hline
\end{tabular}




\begin{tabular}{|c|c|c|c|c|}
\hline \multirow{5}{*}{ Zhu et al. (2013) } & \multirow{4}{*}{ Harbin, China } & \multirow{4}{*}{$\mathrm{n}=240$} & \multirow{2}{*}{$\begin{array}{c}\text { Bedroom } \\
\text { Living room }\end{array}$} & \multirow{2}{*}{$\begin{array}{c}50 \\
100\end{array}$} \\
\hline & & & & \\
\hline & & & Kitchen & 30 \\
\hline & & & Study room & 110 \\
\hline & & & Mean & 72.5 \\
\hline \multirow[t]{2}{*}{ Zhou et al. (2011) } & Tianjing, China & $\mathrm{n}=10$ & & 54 \\
\hline & & & Bedroom & 33.5 \\
\hline \multirow[t]{3}{*}{ Guo et al. (2013) } & Dalian, China & $\mathrm{n}=59$ & Kitchen & 32.3 \\
\hline & & & Mean & 32.9 \\
\hline & & & Bedroom & 23.2 \\
\hline \multirow[t]{2}{*}{ Cheng et al. (2018) } & Chongqing, China & $\mathrm{n}=50$ & Living room & 21.3 \\
\hline & & & Kitchen & 15.6 \\
\hline Jouni et al. (2011) & Helsinki, Finland & $\mathrm{n}=15$ & & 39.96 \\
\hline Marchand et al. (2008) & Strasbourg, France & $\mathrm{n}=143$ & & 32.3 \\
\hline \multirow[t]{2}{*}{ Nicolas et al. (2006) } & Quebec, Canada & $\mathrm{n}=96$ & & 29.5 \\
\hline & Los Angeles, USA & $\mathrm{n}=73$ & & \\
\hline \multirow[t]{2}{*}{ Hun et al. (2010) } & Elizabeth, USA & $\mathrm{n}=58$ & Mean & 20.64 \\
\hline & Houston, USA & $\mathrm{n}=48$ & & \\
\hline Sax et al. (2006) & Los Angeles, USA & $\mathrm{n}=41$ & & 19.3 \\
\hline Sax et al. (2006) & New York, USA & $\mathrm{n}=46$ & & 17.7 \\
\hline Molloy et al. (2012) & Melbourne, Australia & $\mathrm{n}=40$ & & 14.64 \\
\hline
\end{tabular}

The concentration levels of formaldehyde in Chongqing's residences were relatively low compared to those in other Chinese cities because the measured residences were compliant with the mandatory standard and without any renovation within the last year.

\subsection{Occupancy characteristics}

In this study, we measured the $\mathrm{CO}_{2}$ concentration in 3 functional rooms, namely the living room, bedroom, and kitchen. By analyzing the real-time $\mathrm{CO}_{2}$ concentration data together with the information sheet completed by the occupants, the time distribution in residences was obtained. The ascending and descending segments of the $\mathrm{CO}_{2}$ concentration curve can directly reflect whether the room was occupied. Almost 
every measured family has one young kid, and one retired people who took care of the young kid. It is common in China that three generation live in one flat and grandparents look after their grandchild. In addition, Chinese people have a habit of eating hot dishes for lunch and sleeping after lunch at home. According to this situation, the measured residences have human activities most of the time.

Compared with the $\mathrm{CO}_{2}$ concentration data for the 42 residences, it was easy to define the time period occupants spent in different functional rooms. Table 5 present the overall situation of occupants time distribution in different functional rooms. Occupants always stay at home during these periods.

Table 5: People occupancy schedule in Chongqing residences by real-time $\mathrm{CO}_{2}$ concentration data

\begin{tabular}{cc}
\hline Different functional rooms & Time distribution \\
\hline Living room & $7: 30 \mathrm{am}-8 \mathrm{am} ; 12 \mathrm{midday}-1 \mathrm{pm} ; 7: 30 \mathrm{pm}-10: 30 \mathrm{pm}$ \\
Bedroom & $10: 30 \mathrm{pm}-7 \mathrm{am} ; 1 \mathrm{pm}-2 \mathrm{pm}$ \\
Kitchen & $7 \mathrm{am}-7: 30 \mathrm{am} ; 11 \mathrm{am}-12$ midday; 6:30pm-7:30pm \\
\hline
\end{tabular}

The person's lifetime distribution statistical data can also be calculated from "Time Use Patterns in China"[55] (Table 6) which provides people's time use patterns in different environments in different Chinese cities.

Table 6: People occupancy schedule in Chongqing residences by "Time Use Patterns in China"

\begin{tabular}{ccc}
\hline Parameters & Male & Female \\
\hline Occupancy schedule in residence (min/day) & 932 & 1018 \\
Living room & $27.3 \%$ & $30 \%$ \\
Bedroom & $57.4 \%$ & $53.2 \%$ \\
Kitchen & $15.3 \%$ & $16.8 \%$ \\
\hline
\end{tabular}

The time fraction for each room was calculated using real-time $\mathrm{CO}_{2}$ concentration data and proved to be very similar to Table 6 which is based on the occupancy schedule in Chongqing residences calculated using "Time Use Patterns in China". This means the time distribution of occupants who lived in the measured residential apartments were 
consistent with the time distribution data for the Chongqing urban area.

The whole day was separated into two parts in this study and the occupants' time distribution categorized accordingly into day-time and night-time. For the living room, 12:00 midday to $1 \mathrm{p} . \mathrm{m}$. and 7:30p.m. to $10: 30 \mathrm{p} . \mathrm{m}$. were selected as the daytime and nighttime patterns, respectively; for the bedroom, there were only two time periods, 10:30p.m.-7a.m.; 1p.m.-2p.m.; for the kitchen, 11:00 a.m. to 12:00 midday and 6:30p.m. to 7:30p.m. were chosen as the daytime part and nighttime part, respectively. This occupancy pattern ensures that during these time period, there are always occupants staying at home.

People's metabolism makes the human body a source of pollution, and people can emit VOCs such as formaldehyde (the primary emission from the skin ${ }^{[56]}$ ) within their exhaled breath ${ }^{[6]}$.

There is sufficient information in the literature to develop reasonable statistical models for human breath emissions. In this study, an individual's formaldehyde breath emission rate was obtained from the literature. The emission rate per-occupant of 4.06 $\mu \mathrm{g} / \mathrm{h} / \mathrm{occ}$, which is based on data from Rackes et al. ${ }^{[30]}$, was used. The number of occupants in rooms was also recorded $(3 \pm 1$ (mean $\pm \mathrm{SD})$ ). The number of occupants in the residences for each sampling duration were collected by questionnaire. 


\subsection{Air exchange rate}

To compare the differences in indoor and outdoor concentrations and the differences between night and daytime, the continuous 24-hour data were averaged as shown in Fig. 5. Using the average $\mathrm{CO}_{2}$ concentration to describe the residence $\mathrm{CO}_{2}$ concentration level is more accurate than the time dependent values. During some periods for example, the $\mathrm{CO}_{2}$ concentration is very low in some rooms, e.g. the kitchen when people are not cooking. The average $\mathrm{CO}_{2}$ concentration can express the overall level of indoor $\mathrm{CO}_{2}$ concentration. The use of $\mathrm{CO}_{2}$ averaged over the whole household could better match the formaldehyde measurement for the whole apartment as well.

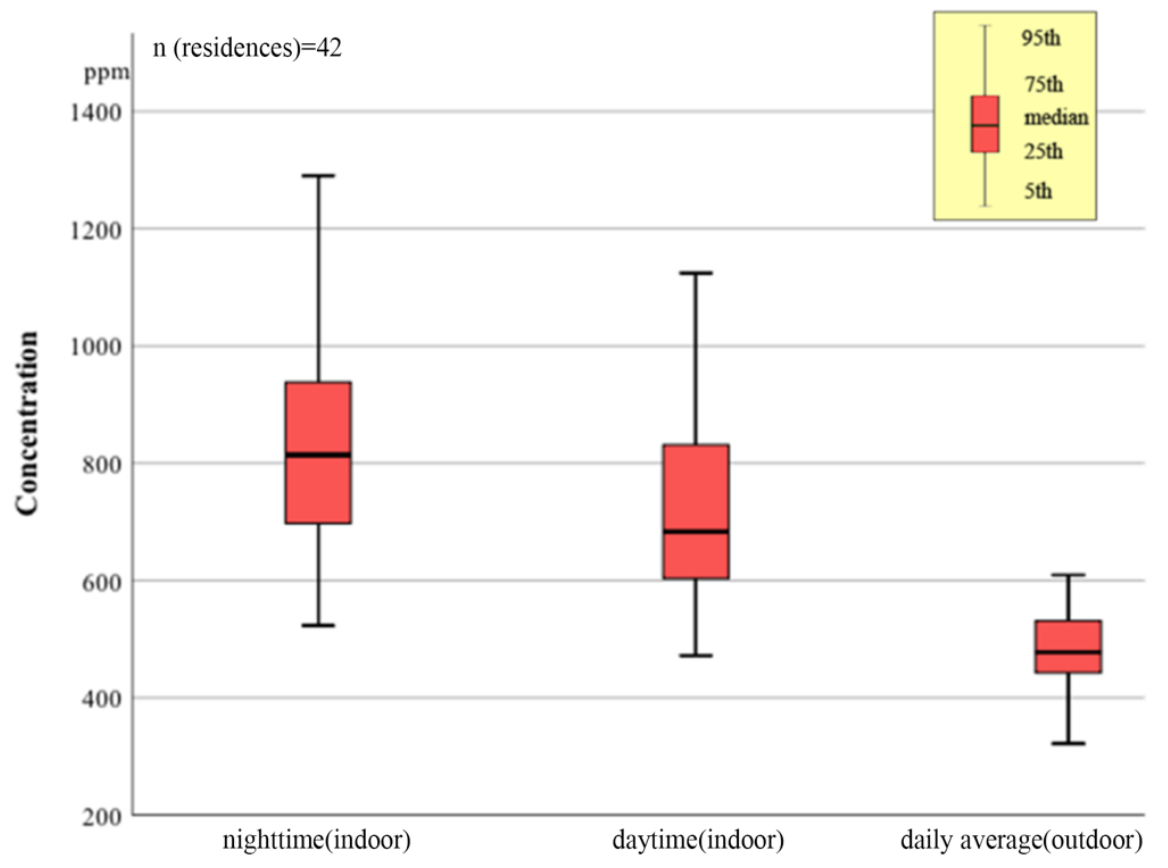

Fig. 5: The concentrations of $\mathrm{CO}_{2}$

From Fig. 5 we can see that the mean concentrations of indoor $\mathrm{CO}_{2}$ during nighttime, day-time, and outdoors were 753ppm, 705ppm, and 475ppm respectively. The outdoors $\mathrm{CO}_{2}$ concentration had the lowest value. Sometimes, the indoor $\mathrm{CO}_{2}$ 
concentration was found to exceed the threshold of 1000ppm in the 'Chinese National Standard (GB/T 18883-2002), ${ }^{[38]}$.

Chongqing is located in the southwest of China on the upper-middle reaches of the Yangtze River. It has a monsoon-influenced, humid, subtropical climate similar to Shanghai, experiencing very wet conditions for most of the year. Winters in Chongqing are short and somewhat mild, but damp and overcast. All the measurements in this study were conducted during winter at a time when there were no central heating systems used in Chongqing. People in Chongqing mostly opened the windows (natural ventilation) to refresh the indoor air during the daytime and closed them to keep warm when they stayed at home ${ }^{[57]}$, which may cause the $\mathrm{CO}_{2}$ concentrations to be higher during the night-time than that in the daytime.

In this study, the per-capita living space in urban residences in Chongqing is $38.0 \pm 11.0 \mathrm{~m}^{2}$. According to the Chinese standard 'Design Code for Heating Ventilation and Air Conditioning Of Civil Buildings' (GB 50736-2012) ${ }^{[58]}$, when the per-capita living space is between $20 \mathrm{~m}^{2}$ and $50 \mathrm{~m}^{2}$, the ventilation air flow rate should be $0.5 \mathrm{~h}^{-1}$; when the per-capita living space is more than $50 \mathrm{~m}^{2}$, the ventilation air flow rate should be $0.45 \mathrm{~h}^{-1}$. 


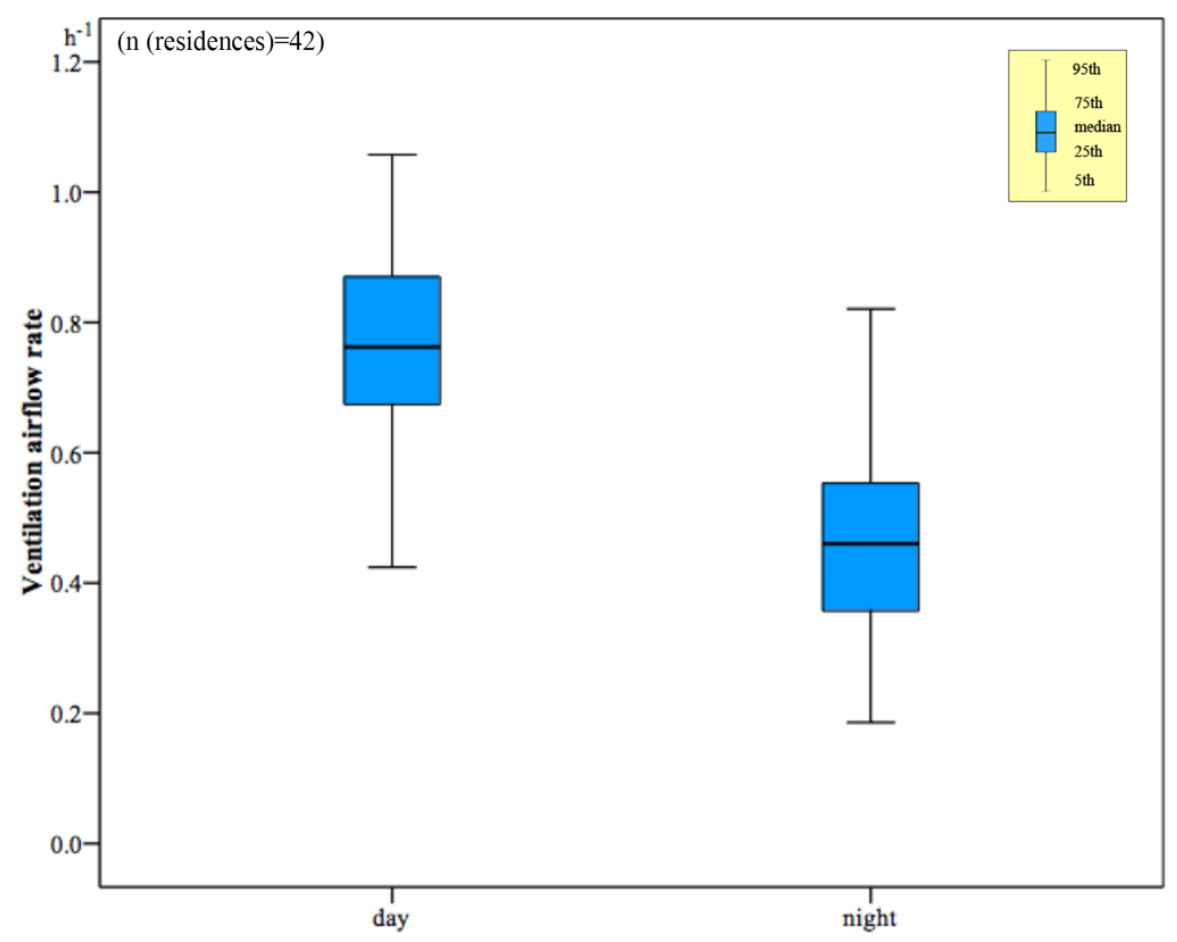

Fig. 6: Ventilation airflow rate.

Because we measured the $\mathrm{CO}_{2}$ concentration in at least 3 rooms (the living room, bedroom, and kitchen) in each residence, we calculated ventilation airflow rate for each room and also used the average $\mathrm{CO}_{2}$ concentration to calculate the real ventilation airflow rate for the dwelling. The relative error is around $10 \%$. With the low ventilation airflow rate, if the concentration levels of $\mathrm{CO}_{2}$ in different functional rooms are different, the mixing of the indoor air might not have been very good, hence the difference.

According to Fig. 6, the maximum value of the ventilation airflow rate during daytime was $1.39 \mathrm{~h}^{-1}$ and the minimum value was $0.43 \mathrm{~h}^{-1}$, giving a mean value of $0.79 \pm 0.20(\mathrm{SD}) \mathrm{h}^{-1}$. The maximum value of the ventilation airflow rate at night was $0.83 \mathrm{~h}^{-}$ , and the minimum value was $0.19 \mathrm{~h}^{-1}$, giving a mean value of $0.46 \pm 0.13(\mathrm{SD}) \mathrm{h}^{-1}$. At night, for most of the residences, the air exchange rate was higher than $0.4 \mathrm{~h}^{-1}$, but there were still $32.7 \%$ residences with an air exchange rate lower than $0.4 \mathrm{~h}^{-1}$. Compared to 
the critical value of $0.5 \mathrm{~h}^{-1}$, the $25^{\text {th }}$ percentile value of the daytime ventilation airflow rate was over $0.6 \mathrm{~h}^{-1}$, and the $5^{\text {th }}$ percentile value was lower than $0.5 \mathrm{~h}^{-1}$; the $5^{\text {th }}$ percentile value, $25^{\text {th }}$ percentile value and median value of the night ventilation airflow rate were lower than $0.5 \mathrm{~h}^{-1}$ whilst the $75^{\text {th }}$ percentile value was over $0.5 \mathrm{~h}^{-1}$. At night, the lower ventilation airflow rate did not meet the GB 50736-2012 standard hence the pollutants would have been retained in the indoor environment and could not effectively be exhausted to the outside.

Because people stay and sleep at home at night, the air quality at night would have more influence on human health. During the night, the windows and doors were closed and the ventilation rate low, which could lead to an increased pollutant concentration ${ }^{[59]}$.

\subsection{Emission rates}

Emission sources in the indoor environment are very unpredictable and consist of various categories. This makes it difficult to calculate the emission rates for every source. A time-averaged effective emission rate calculated per $\mathrm{m}^{2}$ of floor area was used to predict the formaldehyde emission rate in residences. Table 7 lists the parameters that are used for the Monte Carlo assessments.

Table 7: Summary of the building characteristics and environmental parameters $(n=25)$

\begin{tabular}{ccccc}
\hline \multicolumn{2}{c}{ Parameters } & Median & Mean & SD \\
\hline \multirow{2}{*}{$N_{\text {vent }}\left(\mathrm{h}^{-1}\right)$} & Daytime & 0.83 & 0.86 & 0.17 \\
& Night & 0.52 & 0.50 & 0.13 \\
& Mean & 0.68 & 0.68 & 0.24 \\
The number of occupants & 3 & 3 & 1
\end{tabular}




$\begin{array}{cccc}C_{\text {in }}\left(\mu \mathrm{g} / \mathrm{m}^{3}\right) & 32.01 & 34.87 & 8.71 \\ C_{\text {out }}\left(\mu \mathrm{g} / \mathrm{m}^{3}\right) & 25.00 & 25.04 & 4.75 \\ \text { Area of residence }\left(A_{a}, \mathrm{~m}^{2}\right) & 100.00 & 98.72 & 31.13\end{array}$

To assess the emission rate, the daytime emission rate and nighttime emission rate were considered separately, and the average emission rate obtained.

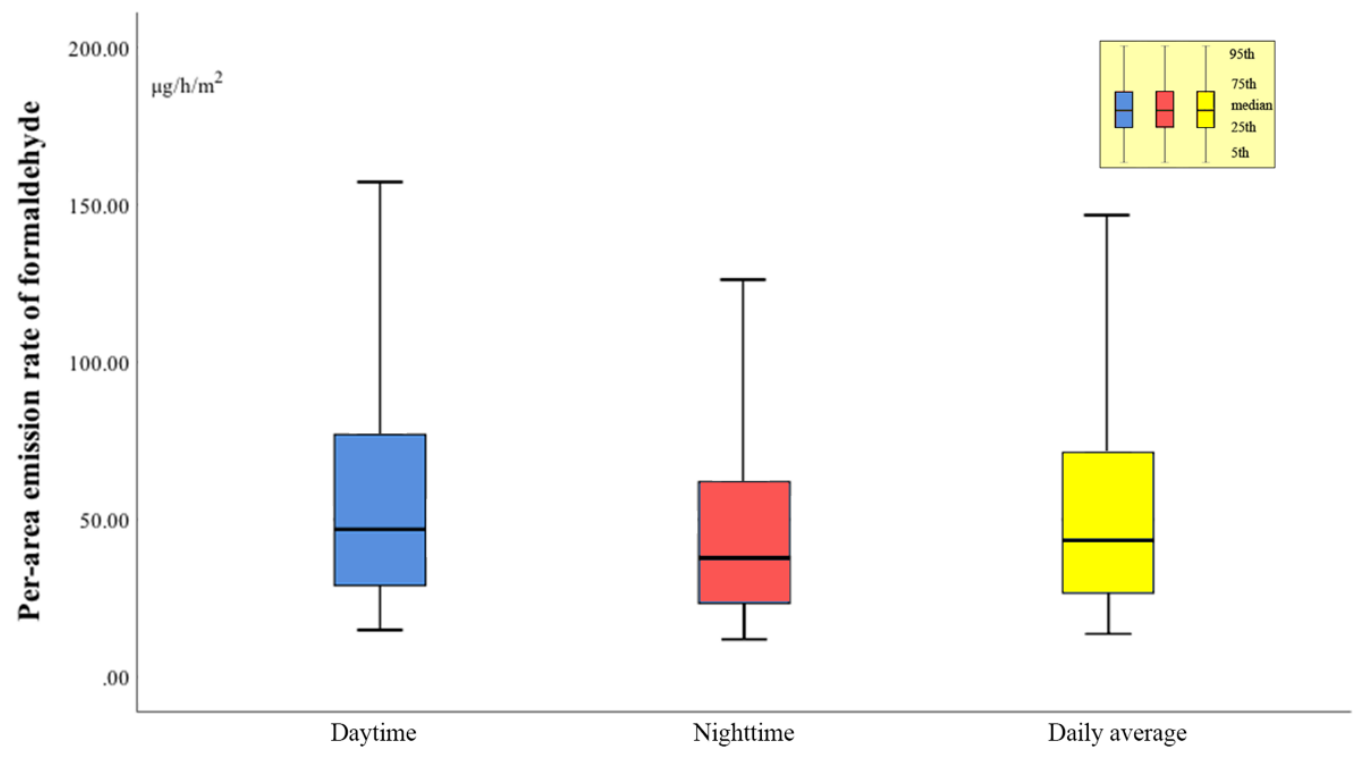

Fig. 7: Emission rates.

The value of the emission rate calculated from Equation 12 was very small and even negative in some cases; i.e. outdoor formaldehyde concentrations may be higher than indoor concentrations. To avoid this situation, the concentrations were compared before calculation, and when the indoor concentration was smaller than that outdoors, this data was removed. This situation appeared in 17 measured residences, hence we used the rest of the data on indoor and outdoor formaldehyde concentrations and ventilation rates for the rest of residences ( 25 in total) to calculate the emission rate.

According to Fig. 7, the daytime emission rate is $61.82 \pm 52.39 \mu \mathrm{g} / \mathrm{h} / \mathrm{m}^{2}($ mean $\pm \mathrm{SD})$, the night emission is $49.69 \pm 42.13 \mu \mathrm{g} / \mathrm{h} / \mathrm{m}^{2}$ (mean \pm SD) and the average emission is $57.20 \pm 48.79 \mu \mathrm{g} / \mathrm{h} / \mathrm{m}^{2}($ mean $\pm \mathrm{SD})$. The range of emission rates was wide, one of the reasons being that the quality of building materials, such as wallpaper, wardrobes, and 
cabinets, might be different in different residences. The sensitivity analysis indicates that the indoor and outdoor concentrations are two decisive factors for the emission rate. When the ventilation rate is low, the indoor emission sources are the most important for the determining the indoor formaldehyde concentration; however, if the ventilation rate is high, the outdoor concentration becomes the most important source.

In this study, we separated the indoor sources into two groups; one is the main source - like consumer products, building and decoration materials - and the other one is the human emission source. By calculating the contribution of human formaldehyde emission and comparing this with the other main sources, the human emission can in some cases be ignored. In residences, the number of occupants is mostly lower than 10 , making the contribution of human emission lower than $1 \%$.

\subsection{Sensitivity analysis}

Fig. 8 shows the influence of different factors on the formaldehyde emission rate. According to this figure, the concentration difference between indoors and outdoors is the most significant factor (around 64\%) that influences the emission rate, whereas the contribution from the residents is around $35 \%$, with the air exchange rate having the lowest influence (lower than $2 \%$ ). That is, formaldehyde released from humans has no significant impact on the emission rate level. Hence, to control the indoor air pollutant concentration, controlling the source of the pollutant has a better effect on reducing the indoor concentration than increasing the air exchange rate, which means that using building materials that emit less formaldehyde can significantly lower the indoor pollutant concentration. Natural ventilation may not be the best way to reduce the indoor formaldehyde concentration because the indoor and outdoor concentrations are just slightly different; using an air cleaner and filter might have a better, more efficient, 
effect for improving the indoor environment.

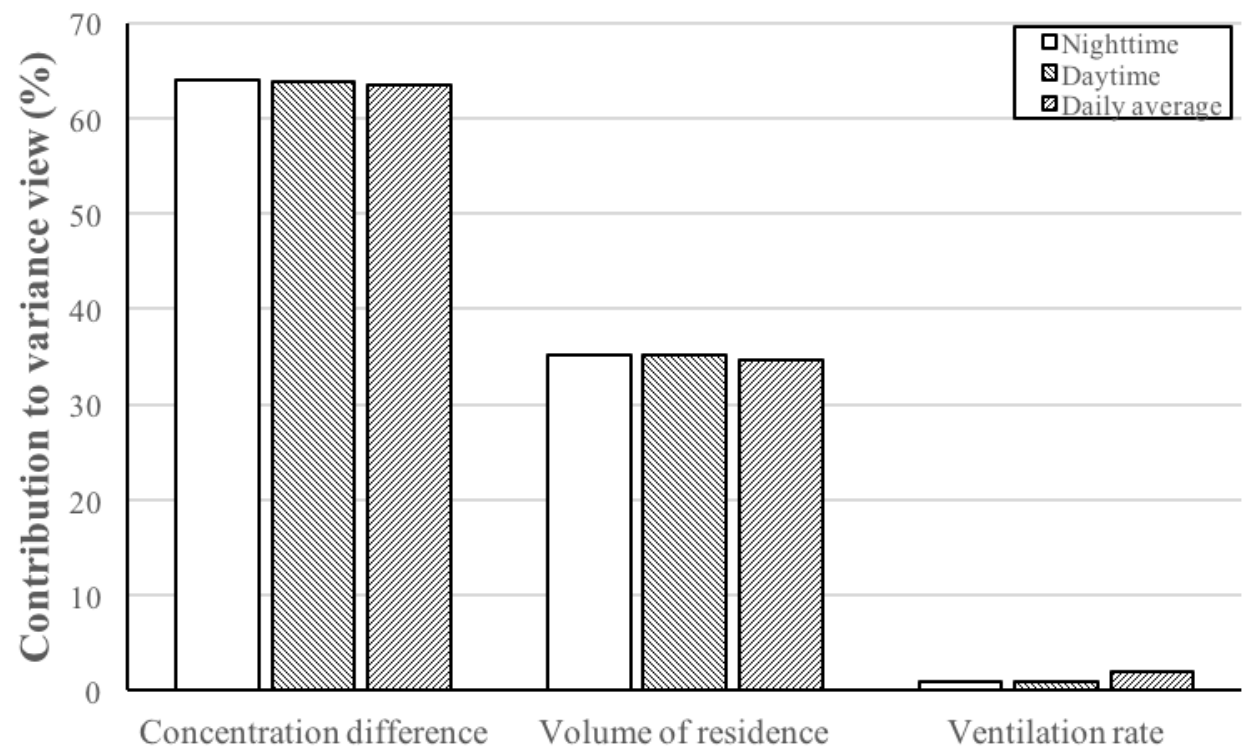

Fig. 8: Contribution to the emission rate.

\section{Conclusions}

This study measured the formaldehyde and $\mathrm{CO}_{2}$ concentrations in residential buildings in Chongqing, China to provide a better understanding of indoor formaldehyde pollution and understand its emission sources using on-site measurement and a numerical approach. A robust prediction model for formaldehyde using $\mathrm{CO}_{2}$ concentration as tracer gas has been developed. The effect of formaldehyde emissions from humans and its affect on the indoor concentration was also investigated. Results indicate that:

- The concentration levels of formaldehyde in Chongqing's residences built between 2005 and 2012 without any interior decoration were relatively low compared to other Chinese cities. The indoor concentration of formaldehyde was slightly higher than that in the outdoor environment. The significant 
contribution to indoor concentration levels was from indoor sources.

- The average emission rate in urban Chongqing residences is about $57.20 \pm 48.79 \mu \mathrm{g} / \mathrm{h} / \mathrm{m}^{2}($ mean $\pm \mathrm{SD})$, a value that is rather high compared to previous studies ${ }^{[32][33]}$. During day-time hours, the emission rate is slightly higher than that at night-time. This might be due to differences in ventilation rates and personal activity during these two different periods.

- The occupants' formaldehyde emissions can be ignored in residences, due to their negligible contribution to the total emissions. However, in some spaces with a high population density, like the cabin of a plane, a train, bus or club, human emission rates of formaldehyde should be taken into consideration.

\section{Limitations}

In this study, all the measurements were conducted in winter. The emission of pollutants from building materials was highly correlated to the local temperature. Simultaneous data could be used to calculate the emission rate in future studies to investigate the real-time emission rates when the window and door status as well as occupants' activities, like cooking and smoking, are available. To study the influence of outdoor formaldehyde concentration levels on the indoor environment, the relationship between the indoor and outdoor air qualities should be further studied.

\section{Acknowledgements}

We thank the Institute of International Education funded Global Innovation Initiative (GII) Project "The impact of ambient air pollution on indoor environment in 
China: Evaluation of a practical intervention" (Grant No. EGA/A.S/S-13-05) and the UK China collaborative research funded by the National Natural Science Foundation of China and UK Engineering and Physical Sciences Research Council "Low carbon climate-responsive Heating and Cooling of Cities (LoHCool)" (NSFC 51561135002/ EPSRC EP/N009797/1) for their financial support. We would like to thank all the members of the indoor air quality group in Chongqing University and all the volunteers participating in this study. The authors wish to express their special thanks to Professor Guangyu Cao from the Norwegian University of Science and Technology and Jiahui Wang and Nuoa Lei for providing technical support. We would like to thank Prof. Hazim Awbi for his proofreading of the second revised version. 


\section{References}

[1] Tang XJ, Bai Y, Duong A, Smith M, Li LY, et al. Formaldehyde in China: production, consumption, exposure levels, and health effects. Environ Int35 (2009): 1210-1224.

[2] Zhang LP, Crag Steinmaus, et al. Formaldehyde exposure and leukemia: A new meta-analysis and potential mechanisms. Mutation Research 681 (2009):150-168

[3] Chemical Economics Handbook: Formaldehyde. HIS Markit, 2017

[4] Huang LH, Mo JH, Sundell J, Fan ZH, Zhang YP. Health Risk Assessment of Inhalation Exposure to Formaldehyde and Benzene in Newly Remodeled Buildings, Beijing. PLoS ONE 2013 8(11): 79553. doi: 10.1371/journal.pone.0079553

[5] Trantallidi M, Dimitroulopoulou C, Wolkoff P, Kephalopoulos S, Carrer P. EPHECT III: Health risk assessment of exposure to household consumer products. Science of The Total Environment. 2015;536:903-13.

[6] Filipiak W, Ruzsanyi V, Mochalski P, Filipiak A, Bajtarevic A, Ager C, Denz H, Hilbe W, Jamnig H, Hackl M, Dzien A, Amann A. Dependence of exhaled breath composition on exogenous factors, smoking habits and exposure to air pollutants. J Breath Res. 2012 Sep;6(3):036008. doi: 10.1088/1752-7155/6/3/036008.

[7] Hodgson A T, Rudd A F, Beal D, Chandra S. Volatile Organic Compound Concentrations and Emission Rates in New Manufactured and Site - Built Houses. Indoor Air. 2001;10(3):178-92.

[8] Dodson RE, Houseman EA, Levy J, Spengler J, Shine J, et al. Measured and modeled personal exposures to and risks from volatile organic compounds. Environ Sci Technol 2007 41: 8498-8505.

[9] Brown SK, Sim MR, Abramson MJ, Gray CN. Concentrations of volatile organic compounds in indoor air-A review. Indoor Air 1994, 4: 123-134.

[10] Weschler CJ. Changes in indoor pollutants since the 1950s. Atmospheric Environment 2009, 43: 153-169.

[11] Haghighat F, Lee CS, Ghaly WS. Measurement of diffusion coefficients of VOCs for building materials: review and development of a calculation procedure. Indoor Air, 2002,12: 81-91.

[12] AgBB (2012). Health-related Evaluation Procedure for Volatile Organic Compounds Emissions (VOC and SVOC) from Building Products. Germany, Ausschuss zur gesundheitlichen Bewertung von Bauprodukten.

[13] ECA (2013). Report No. 29. Harmonisation Framework for Health Based Evaluation of Indoor Emissions from Construction Products in the European Union Using the EU-LCI Concept. EUR 26168/EN. Luxembourg: Publications Office of the European Union.

[14] Liu Z, Ye W, Little JC. Predicting emissions of volatile and semi-volatile organic compounds from building materials: A review. Building and Environment, 2013,64: 7-25.

[15] Zhang Y, Xiong J, Mo J, Gong M, Cao J. Understanding and controlling airborne organic compounds in the indoor environment: Mass transfer analysis and applications. Indoor Air, 2016,26: 39-60.

[16] Wei W, Xiong J, Zhao W, Zhang Y. A framework and experimental study of an improved VOC/formaldehyde emission reference for environmental chamber tests. Atmospheric Environment. 2014;82:327-34.

[17] Liang W, Yang X. Indoor formaldehyde in real buildings: Emission source identification, overall emission rate estimation, concentration increase and decay patterns. Building and Environment. 
2013;69:114-20.

[18] JY Xiong, YP Zhang, SD Huang. Characterisation of VOC and Formaldehyde Emission from Building Materials in a Static Environmental Chamber: Model Development and Application. Indoor Built Environ 2011; 20; 2:217-225

[19] Chan, W.R., Parthasarathy, S., Fisk, W.J. and McKone, T.E. Estimated effect of ventilation and filtration on chronic health risks in U.S. offices, schools, and retail stores, Indoor Air,2016, 26, 331343.

[20] Dutton, S.M. and Fisk, W.J.Energy and indoor air quality implications of alternative minimum ventilation rates in California offices, Build. Environ. 2014, 82, 121-127.

[21] Rackes, A. and Waring, M.S. Modeling impacts of dynamic ventilation strategies on indoor air quality of offices in six US cities, Build. Environ. 2013, 60, 243-253.

[22] Long, C. M.; Suh, H. H.; Catalano, P. J.; Koutrakis, P. Using Time- and Size-Resolved Particulate Data To Quantify Indoor Penetration and Deposition Behavior Environ. Sci. Technol. 2001, 35, 2089-2099.

[23] Koponen, I.K.; Asmi, A; Keronen, P; Puhto, K; Kulmala, M. Indoor air measurement campaign in Helsinki, Finland 1999 — the effect of air pollution on indoor air. Atmos. Environ. 2001, 35, 1465 1477.

[24] Abt, E; Suh, H.H; Catalano, P; Koutrakis, P. Relative Contribution of Outdoor and Indoor Particle Sources to Indoor Concentrations. Environ. Sci. Technol. 2000, 34, 3579-3587.

[25] Jones, N.C; Thornton, C.A; Mark, D; Harrison, R.M. Indoor/outdoor relationships of particulate matter in domestic homes with roadside, urban and rural locations. Atmos. Environ. 2000, 34, $2603-$ 2612.

[26] Vette, A.F; Rea, A.W; Lawless, P.A; Rodes, C.E; Evans, G; Highsmith, V.R; Sheldon, L. Characterization of Indoor-Outdoor Aerosol Concentration Relationships during the Fresno PM Exposure Studies. Aerosol Sci. Technol. 2001, 34, 118-126.

[27] Thornburg, J; Ensor, D.S; Rodes, C.E; Lawless, P.A; Sparks, L.E; Mosley, R.B. Penetration of Particles into Buildings and Associated Physical Factors. Part I: Model Development and Computer Simulations. Aerosol Sci. Technol. 2001, 34, 284-296.

[28] Riley, W.J., McKone, T.E., Lai, A.C.K. and Nazaroff, W.W. Indoor particulate matter of outdoor origin: importance of size-dependent removal mechanisms, Environ. Sci. Technol. 2002, 36, 200207

[29] El Orch, Z., Stephens, B. and Waring, M.S. Predictions and determinants of size-resolved particle infiltration factors in single-family homes in the U.S, Build. Environ. 2014, 74, 106-118.

[30] A. Rackes, M. S. Waring. Do time-averaged, whole-building, effective volatile organic compound (VOC) emissions depend on the air exchange rate? A statistical analysis of trends for 46 VOCs in U.S. offices. Indoor Air 2016; 26: 642-659

[31] Turk, B.H., Grimsrud, D.T., Harrison, J., Prill, R.J. (1987) A comparison of indoor air quality in conventional and model conservation standard homes in the Pacific Northwest, Final Report to the Bonneville Power Administration, Lawrence Berkeley Laboratory Report No. LBL-23429.

[32] Sherman MH, Hodgson AT. Formaldehyde as a basis for residential ventilation rates. Indoor Air. 2003;14(1):2-8.

[33] Kim J, Kim S, Lee K, Yoon D, Lee J, Ju D. Indoor aldehydes concentration and emission rate of 
formaldehyde in libraries and private reading rooms. Atmospheric Environment. 2013;71:1-6.

[34] Cheng Z, Li BZ, Yu W, Wang H, Zhang TJW, Xiong J, Bu ZM, Risk assessment of inhalation exposure to VOCs in dwellings in Chongqing, China, Toxicology Research 2018; doi:10.1039/C7TX00191F.

[35] Ministry of Science and Technology of the People's Republic of China. National Science \& Technology Support Project: Technology for Monitoring and Operation of Building Indoor Air Pollution [in Chinese]. 2012. Grant No. 2012BAJ02B06.

[36] GB 50325-2005. Code for indoor environmental pollution control of civil building engineering; 2006 [in Chinese].

[37] Tsinghua University, 'Data analysis report of indoor air quality survey': http://news.tsinghua.edu.cn/publish/thunews/9649/2015/20150423100046963966000/2015042310 0046963966000_.html [in Chinese]

[38] GB/T 18883-2002. Standards for indoor air quality; 2002 [in Chinese].

[39] GB/T 16129-1995. Chinese Standard method for hygienic examination of formaldehyde in air of residential area-spectrophotometric method; 1995 [in Chinese].

[40] Moschandreas D, Watson J, D'Abreton P, Scire J, Zhu T, Klein W, et al. Chapter three: methodology of exposure modeling. Chemosphere 2002; 49:923-46.

[41] Gerd W, Peter MH, Maurice GC, Clemens E. A two-stage procedure for determining the number of trials in the application of a Monte Carlo method for uncertainty evaluation. Metrologia. 2010;47(3):317.

[42] ASTM Standard D 6245-98/02. Using indoor carbon dioxide concentrations to evaluate indoor air quality and ventilation[S]. ASTM International, 2002.

[43] ASTM Standard E 741-00. Standard test method for determining Air exchange in a single zone by means of a tracer gas dilution[S]. ASTM International, 2000.

[44] Ing. P Š. Experimental Evaluation of Ventilation in Dwellings by Tracer Gas CO2[D]. Prague: Czech Technical University: 2011.

[45] GB 50325-2010. Code for indoor environmental pollution control of civil building engineering; 2010 [in Chinese].

[46] Peng Guo, Kazuhito Yokoyama, Fengyuan Piao, Kiyoshi Sakai, Md Khalequzzaman, Michihiro Kamijima, Tamie Nakajima and Fumihiko Kitamura. Sick Building Syndrome by Indoor Air Pollution in Dalian, China, Int. J. Environ. Res. Public Health 2013, 10, 1489-1504; doi:10.3390/ijerph10041489.

[47] Zhou J, You Y, Bai ZP, et al. Health risk assessment of personal inhalation exposure to volatile organic compounds in Tianjin, China. Science of the Total Environment 409 2011; 452-459.

[48] Zhu XD, Liu Y. Characterization and Risk Assessment of Exposure to Volatile Organic Compounds in Apartment Buildings in Harbin, China. Bull Environ Contam Toxicol 2014; 92:96-102.

[49] Jouni Jurvelin, Matti Vartiainen, Matti Jantunen \& Pertti Pasanen, Personal Exposure Levels and Microenvironmental Concentrations of Formaldehyde and Acetaldehyde in the Helsinki Metropolitan Area, Finland, Journal of the Air \& Waste Management Association, 2011, 51:1, 17 24, DOI: 10.1080/10473289.2001.10464251 
[50] Marchand C, Calve SL, Mirabel P, Glasser N, Casset A, Schneider N, et al. Concentrations and determinants of gaseous aldehydes in 162 homes in Strasbourg (France). Atmos Environ 2008;42:505-16.

[51] Nicolas L. Gilbert, Denis Gauvin, Mireille Guay, Marie-E`ve He'roux, Genevie`ve Dupuis, Michel Legris, Cecilia C. Chan, Russell N. Dietz, Beno1^t Le'vesque, Housing characteristics and indoor concentrations of nitrogen dioxide and formaldehyde in Quebec City, Canada, Environmental Research 102,2006, 1-8

[52] Sax SN, Bennett DH, Chillrud SN, Ross J, Kinney PL, Spengler JD. A Cancer Risk Assessment of Inner-City Teenagers Living in New York City and Los Angeles. Environmental Health Perspectives. 2006;114(10):1558-1566. doi:10.1289/ehp.8507.

[53] Hun, D. E., Corsi, R. L., Morandi, M. T. and Siegel, J. A, Formaldehyde in residences: long-term indoor concentrations and influencing factors. Indoor Air, 2010, 20: 196-203. doi:10.1111/j.0905$6947.2010 .00644 \mathrm{x}$

[54] S.B.Molloy, M.Cheng, I.E.Galbally, M.D.Keywood, S.J.Lawson, J.C.Powell, R.Gillett, E.Dunne, P.W.Selleck, Indoor air quality in typical temperate zone Australian dwellings, Atmospheric Environment, 54, 2012, 400-407

[55] NBS. Time Use Patterns in China. Beijing: China Statistics Press: Department of Social Science and Technology Statistics, National Bureau of Statistics; 2010

[56] Acevedo, C.A., Sanchez, E.Y., Reyes, J.G. and Young, M.E. Volatile profiles of human skin cell cultures in different degrees of senescence, J. Chromatogr. B, 2010, 878, 449-455.

[57] Wang, J. Home Ventilation and Its Associations with Asthma and Allergies Among Preschool Children in Chongqing. [M]. Chongqing University: 2015

[58] GB 50736-2012. Design code for heating ventilation and air conditioning of civil buildings; 2012 [in Chinese].

[59] Al-Hemoud A, Al-Awadi L, Al-Khayat A, Behbehani W. Streamlining IAQ guidelines and investigating the effect of door opening/closing on concentrations of VOCs, formaldehyde, and $\mathrm{NO} 2$ in office buildings. Building and Environment. 2018;137:127-37. 